\title{
Analysis of Secondary School Students' Digital Game Addiction and Sportsmanship Behavior Levels According to Various Variables
}

\section{Kürşat HAZAR ${ }^{1}$ Zekihan HAZAR ${ }^{2}$}

'Rectorate, Department of Physical Education and Sports, Nigde Omer Halisdemir Universty, Turkey. ${ }^{2}$ School of Physical Education and Sports, Nigde Omer Halisdemir Universty, Turkey.

Email:zekihanhazar84@gmail.com

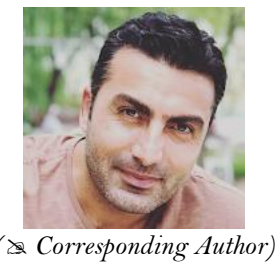

\section{Abstract}

The purpose of this research is to investigate the relationship between digital game addiction and fair play-sportsmanship behavior exhibited in physical education and sports lesson and to reveal the relationship between these two concepts. The research was designed according to the quantitative research model and correlational scanning method was used. Sample: In this research, "typical case" method, one of the purposeful sampling methods, was used. In this context, 500 students (240 females, 260 males) who played digital games every day at least $30 \mathrm{~min}$. and agreed to participate voluntarily in the research were interviewed using face-to-face interviews. Data Collection Personal Information Form, Sportspersonship Behavior Scale in Physical Education Course (SBSPEC), Digital Game Addiction Scale for Children (DGASC) there was used. The data were evaluated in SPSS 24. Package program and subjected to Independent Groups t-Test, ANOVA and Pearson Correlation analyzes. According to the results of the analysis, it was found that there were significant differences in the variables of gender, age, athlete's license and game type. However, there was a positive correlation between the scale scores. Although there is no similar research on the subject when the literature is examined, the findings of the research on the variables discussed in the scope of the research will contribute significantly to the literature in terms of revealing the differences and relationships between the variables.

Keywords: Addiction, Digital game, Digital game addiction, Physical education, Sportsperson ship, Sport

Citation | Kürşat HAZAR; Zekihan HAZAR (2019). Analysis of Secondary School Students' Digital Game Addiction and Sportsmanship Behavior Levels According to Various Variables. Asian Journal of Education and Training, 5(2): 374-380. History:

Received: 22 March 2019

Revised: 29 April 019

Accepted: 4. June 2019

Published: 8 August 2019

Licensed: This work is licensed under a Creative Commons Attribution 3.0 License $($ (c) $)$

Publisher: Asian Online Journal Publishing Group
Acknowledgement: Both authors contributed to the conception and design of the study.

Funding: This study received no specific financial support

Competing Interests: The authors declare that they have no conflict of interests.

Transparency: The authors confirm that the manuscript is an honest, accurate, and transparent account of the study was reported; that no vital study as planned have been explained.

Ethical: This study follows all ethical practices during writing.

\section{Contents}

1. Introduction

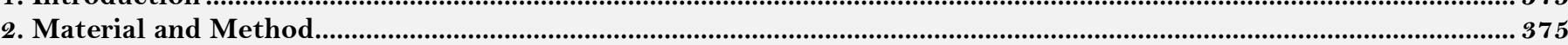

3. Results .

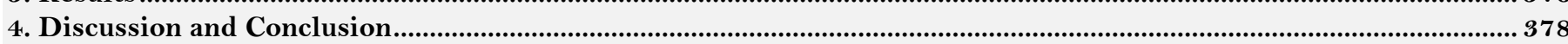

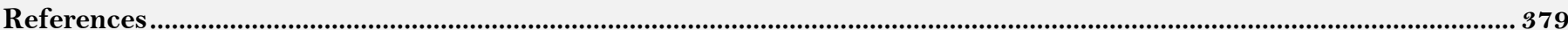




\section{Contribution of this paper to the literature}

This study contributes to the existing literature by investigating the relationship between digital game addiction and fair play-sportsmanship behavior exhibited in physical education and sports lesson and to reveal the relationship between these two concepts.

\section{Introduction}

In today's world, digital games have become one of the activities that children preferred most. In making use of children's leisure time, playing digital games has become more preferable to play sports, read books, go to theater or cinema or spend time communicating directly with other people. In fact, in the long run, the results go back to digital game addiction, which is an important sub-dimension of behavioral addiction. Eryllmaz and Çukurluöz (2018) state that the number of digital addicts increases day by day and that this type of addiction is among the fastest spreading addictions worldwide.

When the literature is examined, it is stated that digital games can have many negative effects on children in terms of cognitive, affective, behavioral and social aspects. When it is examined in terms of psycho-social aspect, digital games fictionalized for the purpose of "winning at all costs", in the long run, may cause to negative feeling and acts such as decrease in sensations, feel lonely, dispatching to fear, decrease in establishing and maintaining relationship among people lying to near abroad about playing games behavior, exhibit obsessive-aggressive behaviors, increase in hostile acts (Horzum et al., 2008; Griffiths and Meredith, 2009; Karayağız-Muslu and Bolışık, 2009; Lieberman et al., 2009; Dolu et al., 2010; Hazar et al., 2017; Demir and Hazar, 2018; Yiğit and Yalman, 2018; Demir and Cicioğlu, 2019). On the other hand, in the real games where interpersonal communication is at the forefront, it can be said that cooperation, helping each other, sharing, compassion, respect and tolerance to the opponent, empathy, acting honestly, fair play-sportsmanship, in short, is at the forefront.

Today, the most important areas where real games involving physical mobility come to life are schools, naturally, physical education and sports lessons. The aim of physical education and sports lesson is to provide healthy development of children in cognitive, affective, behavioral and social aspects. For example; Among the aims of Turkish National Education Basic Law and Turkish National Education, the aims of Physical Education and Sports Lesson are listed as "Appreciating the winner and accepting to lose, being able to take a stand against cheating and injustice (cited from MoNE, Harmandar (2004))". This aim shows that physical education and sports lesson also aims to create fair play-sportsmanship understanding in children. According to Yapan (2007) includes self-control, obeying rules, respect for others, rights, kindness, honor, and generosity; it rejects behaviors that are not accepted by the society such as deceit, disobeying rules and lies.

"Fair-play", known and used in the world with its English name, comprises "sportsmanship in sports". It expresses the ability of individuals to sacrifice themselves by exceeding their egoism and their ability to make concessions and directly favors in sports competitions (Arıpınar and Donuk cited in Güllü (2018)). Fair-Play, shows itself in efforts of athletes during the competition, even under difficult conditions, obeying the rules patiently, consistently and consciously; not accepting unfair advantages in order not to disrupt equality of opportunity; failing to take advantage of the opponent's unfair disadvantages; seeing the opponent not as an enemy but an individual or a partner who actualizes the game and value themselves (Ylldıran, 2004). Pehlivan (2004) states that the concept of fair-play emerges as an expression of respect for human dignity in the first place and that it is a moral reflection of fair and honest play in every stage and every kind of sport.

Based on these definitions; when the goals of Physical Education and Sports courses in which real games are used as basic tools and negative results of digital games are taken into consideration; it can be said that there is a significant contrast on the basis of "fair-play-sportsmanship". When the literature is examined, it can be said that digital games have important effects on interiorizing fair play-unsportsmanlike acts in children. For example, while Lieberman et al. (2009) stated that children who play digital games with violent content become aggressive behaviors in time; Gentile and Anderson (2006) who expressed similar results pointed out that such digital games can lead to negative psychological and social consequences such as the idea of aggression, feeling of aggression, aggressive behavior and decrease in social behavior in the short and long term. Nevertheless, Hazar et al. (2017) found a positive and high-level relationship between digital game addiction and violence in their research.

The purpose of this research is to investigate the relationship between digital game addiction and fair playsportsmanship behavior exhibited in physical education and sports lesson and to reveal the relationship between these two concepts. When the literature is examined; the fact that there is no direct study on the relationship between digital game addiction and fair play-sportsmanship behavior reveals the importance of this research in terms of contribution to the literature.

\section{Material and Method}

The research was designed according to the quantitative research model and correlational scanning method was used. Correlational research is the study where the relationship between two or more variables is examined without intervening in any way (Buyukozturk et al., 2016).

\subsection{Population}

Depending on the purpose of the research, the group of all individuals (units) that can be researched or generalized is called the population (Erkuş, 2013). In this context; the population of this study consists of 1200 students in the 10-14 age group in Niğde Provincial Directorate of National Education 5 February Secondary School in the 2018-2019 academic year.

\subsection{Sample}

In this research, "typical case" method, one of the purposeful sampling methods, was used. Typical sampling method; it requires the identification of a situation typical of a large number of situations in the population related to the research problem and the collection of information on this sample (Buyukozturk et al., 2016). In this context, 
500 students (240 females, 260 males) who played digital games every day at least 30 min. and agreed to participate voluntarily in the research were interviewed using face-to-face interviews. 17 of the obtained scales were not included in the analyzes on the grounds that they would not contribute to the research.

\subsection{Data Collection Tools}

Personal Information Form: As a result of the literature review conducted by the personal information form developed by the researchers, variables such as gender, age, presence of sportsmen license, presence of sports fields close to the place of residence and the type of digital game played were included.

Sportspersonship Behavior Scale in Physical Education Course (SBSPEC): The physical education course sport behavior scale developed by Yakup (2013) for secondary school students is a 5-point Likert type scale. The original scale included 11 items eme Exhibiting Positive Behaviors (EPB) factor (items 1, 2, 4, 7, 9, 11, 12, 14, 16, 19 and 21) and 11 items reversely scored as "Avoiding Negative Behaviors" (NDC). Factor (items 3, 5, 6, 8, 10, 13, 15, 17, 18, 20 and 22); a total of 22 items. The Pearson Moments Multiplication Correlation values of the factors included in the scale were .80 for factor 1 and .78 for factor 2 . The scale is designed to measure the frequency of the behaviors in the items were listed as "(5) Always, (4) Too often, (3) Sometimes (2) Rarely and (1) Never". The lowest score that can be obtained from the scale is 22 (average 1) and the highest score is 110 (average 5). The scores that can be obtained separately from Factor 1 and Factor 2 are the lowest 11 (average 1) and the highest 55 (average 5). It is understood that the higher the scores obtained from the scale, the better the level of sportsmanship of the students.

Digital Game Addiction Scale for Children (DGASC): It was developed by Hazar and Hazar in 2017 with the participation of 10-14 age group students in order to determine the level of digital game addiction of children. The developed scale has four sub-factors and consists of 24 items. The 5-point Likert-type scale was used to evaluate the expressions in the scale $(1=$ Strongly disagree, $\ldots, 5=$ Strongly agree $)$. The lowest score that can be obtained from the scale is "24" and the highest score is "120. In the grading of the scale scoring; "1-24: Normal group, 25-48: Low-risk group, 49-72 Risk group, 73-96 Dependent group, and 97-120 are considered as a Highly dependent group. Scale sub-factors and reliability values for this study are as follows; Excessive Focus and Conflict for Digital Game Playing (.85), Tolerance Development in Game Time and Value Given to Game (.80), Postponement of Individual and Social Tasks / Homework (.82), Psychological-Physiological Reflection of Poverty and Plunge into Game (.88), and Scale item total is (93).

\subsection{Data Analysis}

In the obtained data set, 17 scales were found to be unsuitable for the validity and reliability of the study and were excluded from the data set. The data were evaluated in SPSS 24 Package program and subjected to Independent Groups t-Test, ANOVA and Pearson Correlation analyzes.

\section{Results}

Table-1. DGASC total score of the participants according to gender variable and T-test analysis of sub-factor scores.

\begin{tabular}{|c|c|c|c|c|c|c|}
\hline Scale Scores & Gender & $\mathbf{N}$ & Mean & Std. D. & $\mathbf{t}$ & $\mathbf{p}$ \\
\hline \multirow{2}{*}{ DGASC Total } & Female & 231 & 43,88 & 19,38 & \multirow{2}{*}{$-8,151$} & \multirow{2}{*}{,00 } \\
\hline & Male & 252 & 59,68 & 22,88 & & \\
\hline \multirow{2}{*}{ DGASC 1. Sub-Factor } & Female & 231 & 12,26 & 6,14 & \multirow{2}{*}{$-7,049$} & \multirow{2}{*}{, 00} \\
\hline & Male & 253 & 16,56 & 7,15 & & \\
\hline \multirow{2}{*}{ DGASC 2. Sub-Factor } & Female & 231 & 12,76 & 6,25 & \multirow{2}{*}{$-7,414$} & \multirow{2}{*}{,00 } \\
\hline & Male & 252 & 17,48 & 7,61 & & \\
\hline \multirow{2}{*}{ DGASC 3. Sub-Factor } & Female & 231 & 9,87 & 5,27 & \multirow{2}{*}{$-6,220$} & \multirow{2}{*}{, 00} \\
\hline & Male & 253 & 13,37 & 6,90 & & \\
\hline \multirow{2}{*}{ DGASC 4. Sub-Factor } & Female & 231 & 7,22 & 3,29 & \multirow{2}{*}{$-5,273$} & \multirow{2}{*}{, 00} \\
\hline & Male & 253 & 9,27 & 5,02 & & \\
\hline
\end{tabular}

When Table 1 is examined, it is seen that male participants have higher scores than females in all score types, and this difference is statistically significant.

Table-2. The t-test analysis of gender variable of SBSPEC scores.

\begin{tabular}{|c|c|c|c|c|c|c|}
\hline Scale Scores & Gender & $\mathbf{N}$ & Mean & Std. D. & $\mathrm{t}$ & p \\
\hline \multirow{2}{*}{ SBSPEC Total } & Female & 231 & 86,19 & 15,25 & \multirow{2}{*}{4,816} & \multirow{2}{*}{,00 } \\
\hline & Male & 253 & 79,30 & 16,13 & & \\
\hline \multirow{2}{*}{ SBSPEC 1. Sub-Factor } & Female & 231 & 40,92 & 10,09 & \multirow{2}{*}{1,656} & \multirow{2}{*}{,09 } \\
\hline & Male & 253 & 39,29 & 11,38 & & \\
\hline \multirow{2}{*}{ SBSPEC 2. Sub-Factor } & Female & 231 & 45,27 & 8,25 & \multirow{2}{*}{6,212} & \multirow{2}{*}{,00 } \\
\hline & Male & 253 & 40,00 & 10,18 & & \\
\hline
\end{tabular}

When Table 2 is examined, it is seen that female participants have higher scores than male participants but this difference is seen to be statistically significant in scale total score and 2. Sub-Factor scores. 
Table-3. DGASC total score of the participants according to variable of participants' being licenced and T-test analysis of sub-factor

\begin{tabular}{|c|c|c|c|c|c|c|}
\hline Ölçek Puanları & Athletes' Licence & $\mathbf{N}$ & Mean & Std. D. & $t$ & p \\
\hline \multirow{2}{*}{ DGASC Total } & Yes & 186 & 50,43 & 21,78 & \multirow{2}{*}{$-1,305$} & \multirow{2}{*}{, 19} \\
\hline & No & 297 & 53,19 & 23,19 & & \\
\hline \multirow{2}{*}{ DGASC 1. Sub-Factor } & Yes & 187 & 13,93 & 6,49 & \multirow{2}{*}{$-1,435$} & \multirow{2}{*}{, 15} \\
\hline & No & 297 & 14,87 & 7,31 & & \\
\hline \multirow{2}{*}{ DGASC 2. Sub-Factor } & Yes & 186 & 14,39 & 6,58 & \multirow{2}{*}{$-1,974$} & \multirow{2}{*}{, 04} \\
\hline & No & 297 & 15,75 & 7,80 & & \\
\hline \multirow{2}{*}{ DGASC 3. Sub-Factor } & Yes & 187 & 11,48 & 7,07 & \multirow{2}{*}{,- 592} & \multirow{2}{*}{, 55} \\
\hline & No & 297 & 11,84 & 5,98 & & \\
\hline \multirow{2}{*}{ DGASC 4. Sub-Factor } & Yes & 187 & 8,27 & 5,18 & \multirow{2}{*}{,- 090} & \multirow{2}{*}{, 92} \\
\hline & No & 297 & 8,30 & 3,83 & & \\
\hline
\end{tabular}

${ }^{*} \mathrm{p}<0,05$.

When Table 3 is examined, it is seen that participants score averages significantly differ only in 2 . Sub-Factor and this difference are seen to be in favor of the participants who do not have a licence.

Table-4. SBSPEC total scores of the participants according to the variable of participants' being licensed and T-test analysis of subfactor scores.

\begin{tabular}{|c|c|c|c|c|c|c|}
\hline Scale Scores & Athletes' Licence & $\mathbf{N}$ & Mean & Std. D. & $\mathrm{t}$ & p \\
\hline \multirow{2}{*}{ SBSPEC Total } & Yes & 187 & 81,99 & 15,47 & \multirow{2}{*}{,- 649} & \multirow{2}{*}{, 51} \\
\hline & $\mathrm{No}$ & 297 & 82,96 & 16,46 & & \\
\hline \multirow{2}{*}{ SBSPEC 1. Sub-Factor } & Yes & 187 & 39,71 & 9,58 & \multirow{2}{*}{,- 574} & \multirow{2}{*}{, 56} \\
\hline & No & 297 & 40,29 & 11,52 & & \\
\hline \multirow{2}{*}{ SBSPEC 2. Sub-Factor } & Yes & 187 & 42,27 & 9,27 & \multirow{2}{*}{,- 438} & \multirow{2}{*}{,66 } \\
\hline & No & 297 & 42,67 & 9,92 & & \\
\hline
\end{tabular}

When Table 4 is examined, it is seen that there is a significant difference in SBSPEC total scores of the participants.

Table-5. DGASC total score of the participants according to the type of the games the participants play and T-test analysis of sub-factor scores.

\begin{tabular}{|c|c|c|c|c|c|c|}
\hline Scale Scores & Game Type & $\mathbf{N}$ & Mean & Std. D. & $t$ & $\bar{p}$ \\
\hline \multirow{2}{*}{ DGASC Total } & Violence & 237 & 59,52 & 22,18 & \multirow{2}{*}{7,415} & \multirow{2}{*}{, 00} \\
\hline & Competition & 246 & 45,00 & 20,82 & & \\
\hline \multirow{2}{*}{ DGASC 1. Sub-Factor } & Violence & 238 & 16,60 & 7,04 & \multirow{2}{*}{6,725} & \multirow{2}{*}{, 00} \\
\hline & Competition & 246 & 12,49 & 6,38 & & \\
\hline \multirow{2}{*}{ DGASC 2. Sub-Factor } & Violence & 237 & 17,96 & 7,66 & \multirow{2}{*}{8,588} & \multirow{2}{*}{, 00} \\
\hline & Competition & 246 & 12,58 & 6,02 & & \\
\hline \multirow{2}{*}{ DGASC 3 Sub-Factor } & Violence & 238 & 13,10 & 5,93 & \multirow{2}{*}{4,812} & \multirow{2}{*}{,00 } \\
\hline & Competition & 246 & 10,35 & 6,59 & & \\
\hline \multirow{2}{*}{ DGASC 4. Sub-Factor } & Violence & 238 & 9,01 & 3,81 & \multirow{2}{*}{3,568} & \multirow{2}{*}{, 00} \\
\hline & Competition & 246 & 7,60 & 4,80 & & \\
\hline
\end{tabular}

When Table 5 is examined, it is seen that the scores obtained from DGASC are in favor of the participants who play violent games according to the game types that the participants play, and this difference is statistically significant.

Table-6. SBSPEC total score according to the type of games played by the participants and T-test analysis of sub-factors

\begin{tabular}{|c|c|c|c|c|c|c|}
\hline Scale Scores & Game Type & $\mathbf{N}$ & Mean & Std. D. & $\mathbf{t}$ & p \\
\hline \multirow{2}{*}{ SBSPEC Total } & Violence & 238 & 80,71 & 15,88 & \multirow{2}{*}{$-2,537$} & \multirow{2}{*}{, 01} \\
\hline & Competition & 246 & 84,40 & 16,08 & & \\
\hline \multirow{2}{*}{ SBSPEC 1. Sub-Factor } & Violence & 238 & 39,69 & 11,09 & \multirow{2}{*}{,- 750} & \multirow{2}{*}{, 45 } \\
\hline & Competition & 246 & 40,43 & 10,53 & & \\
\hline \multirow{2}{*}{ SBSPEC 2. Sub-Factor } & Violence & 238 & 41,02 & 10,14 & \multirow{2}{*}{$-3,393$} & \multirow{2}{*}{, OO } \\
\hline & Competition & 246 & 43,97 & 8,97 & & \\
\hline
\end{tabular}

When Table 6 is examined, it is seen that SBSPEC total scores and 2. Sub-Factor scores are in favor of the ones who play "Competition Games" according to the game types played by the participants, and this difference is seen to be statistically significant.

Table-7. ANOVA results of DGASC total scores of the participants according to the participants' age variable.

\begin{tabular}{|c|c|c|c|c|c|c|c|}
\hline Scale & Age & $\overline{\mathbf{N}}$ & Mean & Std. D. & $\mathbf{F}$ & $\mathbf{p}$ & Significant Difference \\
\hline \multirow{5}{*}{ DGASC Total } & 10,00 & 37 & 51,69 & 25,09 & \multirow{5}{*}{3,135} & \multirow{5}{*}{,01 } & \multirow{5}{*}{$14^{*}-11$} \\
\hline & 11,00 & 103 & 47,41 & 23,06 & & & \\
\hline & 12,00 & 166 & 50,67 & 21,08 & & & \\
\hline & 13,00 & 101 & 54,71 & 22,32 & & & \\
\hline & 14,00 & 77 & 58,38 & 23,51 & & & \\
\hline
\end{tabular}

*p<0,05. Groups in favor of score difference are indicated by $(*)$. 
When Table 7 is examined it is seen that participants in 14 age group have higher scale total scores than 11 age group, and this difference is seen to be statistically significant. It is stated that there is no statistically significant difference among other age groups.

Table-8. ANOVA results on sportsmanship total scores of the participants according to age variable.

\begin{tabular}{l|c|c|c|c|c|c|c}
\hline Scale & Age & N & Mean & Std. D. & F & p & Significant Difference \\
\hline \multirow{4}{*}{ SBSPEC Total } & 10,00 & 37 & 85,47 & 17,62 & & & \\
& 11,00 & 103 & 84,64 & 16,72 & & & \\
& 12,00 & 166 & 84,75 & 16,29 & \multirow{3}{*}{4,851} & \multirow{2}{*}{, 00} & \multirow{2}{*}{$10^{*}, 11^{*}, 12^{*}-14$} \\
\cline { 2 - 7 } & 13,00 & 101 & 80,61 & 14,23 & & & \\
\cline { 2 - 6 } & 14,00 & 77 & 76,40 & 14,60 & & & \\
\hline
\end{tabular}

When Table 8 is examined, it is found that the participants in 10,11,12 age groups have higher scale total scores than the ones in 14 age group, and this difference is seen to be statistically significant.

Table-9. Pearson correlation analyses of the participants' DGASC total scores, SBSPEC total score, and age variable

\begin{tabular}{c|c|c|c|c}
\hline Variables & DGASC Total & SBSPEC Total & Age & p \\
\hline DGASC Total & 1 &,$- 312^{* *}$ &, $138^{* *}$ &, $\mathbf{0 0}$ \\
\hline SBSPEC Total & & 1 &,$- 175^{* *}$ &, $\mathbf{0 0}$ \\
\hline Age & & & 1 & \\
\hline p $<0,05$. & &
\end{tabular}

When Table 9 is examined, it is seen that there is a negative but statistically high correlation between the participants' DGASC total scores and SBSPEC scale total scores; and there is a positive and statistically high correlation between DGASC total score and age variable. It is found that there is a negative but statistically high correlation between SBSPEC scale total score and age variable of the participants.

\section{Discussion and Conclusion}

In this part of the research; the results of the statistical analyses will be discussed in light of the literature.

In the study, first of all, comparisons were made regarding the scores obtained from the DGASC according to the gender variable of the participants. When the analyses result in Table-1 are examined; The scale mean score of the male participants are seen to be higher in all score types than the female participants and this difference is statistically significant. Although digital games can now be played with a smartphone or derivative devices easily accessible to men and women; the fact that more male-dominated areas such as digital gaming halls that take this a step further may be an important factor in explaining this situation. When the literature is examined, it is seen that there are similar results in many studies on the subject and the researchers try to explain the main reason of this situation on the grounds that digital games are mostly male-dominated game types (Horzum, 2011; Gökçearslan and Durakoğlu, 2014; Hazar et al., 2017; Kocaman et al., 2017; Bülbül et al., 2018).

When the analyses of the participants' sportsmanship behavior scores according to the gender variable in Table- 2 are examined; it is seen that the mean scores of female participants were higher in all score types than male participants, but this difference is statistically significant in the scale total score and the 2nd sub-factor scores. These results show that female participants have more sportsmanship-fair play behaviors than men. Among the main reasons for this situation, because of the structural characteristics of women (hormonal characteristics, temperament, personality), it can be shown that they have more fair play behavior characteristics than men. When the literature is examined, there are many studies showing that women tend to exhibit less aggressive behaviors than men because of their structural characteristics. For example; Güllü (2018) in the research on the trainerathlete relationship of the athletes and sportsmanship tendencies; it was found that female participants had higher sporting tendencies than male participants. Giles and Heyman (2005) according to the results of the study in which adolescents examined the relationship between gender and aggression; the level of aggression of male participants was higher than female participants. Tiryaki (1996) stated that male individuals were more destructive aggressive than female individuals in the dimension of destructive aggression.

When the results of the analysis of the participants' scores obtained from the DGASC are analyzed according to whether or not they have athletes license in Table-3; It was found that the mean scores of the participants were in favor of the participants with athlete license in all score types, but this difference was found to be statistically significant only in the second sub-factor. Although the difference between the scores of the participants was not statistically significant; the lower dependency scores of the participants with an athlete license is an important finding. Sport, which is one of the most important alternative activities especially for children, is one of the important tools for dealing with digital game addiction for children. When the literature is examined; It is stated that sport may have an important role in the fight against addiction problems such as digital game addiction (Davis, 2001; Griffiths, 2009; Hazar, 2016). For example; Aksel (2018) in his study, "Investigation the Relationship Between Secondary School Students' Digital Game Addiction and Self-Control and Social Tendencies" determined that the level of digital game addiction of the participants doing sports was lower than those who do not, and this difference was statistically significant.

When the results of the analysis of the participants' sportsmanship behavior scores are examined according to whether or not they have athletes license in Table-4; there was no statistically significant difference in the total scores of participants. The main reasons for this are; the participation of all students in sports activities, especially physical education and sports lessons and club activities in schools, and the efforts to gain fair play behavior and understanding especially in these activities may explain this result. However, when the literature is examined; it is seen that there are studies which have reached results in the opposite direction. For example, Karafil et al. (2017) in their study on "Investigation of the Effect of Participation in Sports on Physical Education Course Sportsmanship 
Behaviors", found that the sportsmanship behaviors of the participants with sports license were higher than those who did not have sports license.

When Table-5 is examined; according to the type of games played by the participants, all the scores obtained from the DGASC were in favor of the participants who played violent games and this difference was statistically significant. These results show that violent games are more effective than digital games in children's digital game addiction levels. Research shows that digital games, especially the violent ones, lead to virtual-reality confusion in children and play an important role in the long-term detachment of children from real life and thus addiction to digital games (Sakin, 2007; Kim et al., 2013; Arslan et al., 2014; Irmak and Erdogan, 2016). Since the evaluation of the results obtained for another research problem in connection with this research problem would be a more holistic evaluation; it would be appropriate to discuss them together. When Table-6 is examined; It is seen that the total score of the sportsmanship scale and the 2 nd sub-factor scores are in favor of the participants who play "competition type game according to the type of game played by the participants and this difference is statistically significant. One of the main reasons for this may be that violence in digital games is perceived as normal behavior for children. The fact that there is research in the literature to support these results is an important situation. For example; Yiğit and Yalman (2018) state that the elements of violence frequently used in games lead to tendencies such as turning towards violence or seeing violence as normal in children. They also state that messages are sent through digital games that direct child to racism. Kim et al. (2013) state that children face many negative consequences such as social isolation, paranoia, physical weakness, violence and confusion between reality and fantasy due to digital game addiction. Aydoğdu-Karaaslan (2015) in a study about "Digital games and digital violence awareness: a comparative analysis on parents and children", states that children internalize violence in games and adopt the idea that this can be a way to solve problems in real life. Therefore, in general; It can be said that violent digital games increase the level of digital game addiction and cause children to become more prone to violence and cause them to adopt non-sporting behaviors more.

When Table-7 is examined; it was seen that the mean total score of the participants in the 14-year-old group was higher than that of the 11-year-old group and this difference was statistically significant. There was no statistically significant difference between the other age groups. One of the main reasons for this result may be that children have become acquainted with digital games at an early age as well as increasing the playing time and thus the level of addiction. Another main reason for this result is the desire of children to become more independent by moving away from their parents during adolescence, and also tend to show similar-common behaviors towards groups of friends, and playing digital games or conversations about digital games take an important place among these behaviors. Kale and Erşen (2003) state that children begin to move away from their families during adolescence, form strong ties with friends and build these ties on a number of values. When the literature is examined, it is seen that there are many studies supporting these research results. For example; Müller et al. (2015) in their study on "regular game behavior and internet game disorder among young people in Europe" found that there is a linear relationship between addiction level and age variable. Donati et al. (2015) in a study on "Diversity and addiction in games: The relationship between video game diversity and addiction in male adolescents", it was observed that there was a high positive correlation between the video game addiction level of the participants and the diversity of the game and the duration of the gameplay. If this situation is discussed in conjunction with a research problem, when Table 8 is examined; it is seen that the total score average of the participants in the $10,11,12$ age group is higher than the participants in the 14 age group, and this difference is statistically significant. Among the main reasons for this research result, it can be said that adaptation to the social environment may be effective with some hormonal changes that occur with transition to adolescence. When the results of these two problem situations are evaluated together, the increase in the digital game addiction scores of individuals with age and the decrease in sportsmanship scores is an important finding that draws attention to the relationship between these two variables. When the literature is examined, it is seen that there are studies that are similar to the results of the research. Türkmen and Varol (2015) in their study on "Determining the Effect of Physical Education and Sports Course on Forming Sports Behavior on Secondary School Students", they determined that the level of sportsmanship of 6th-grade students was higher than 7 th grade and 8th-grade students. Yurttaş (2016) in his research; in the physical aggression, anger, hostility and verbal aggression sub-dimensions, the mean scores of individuals between the ages of 21-24 were found to be higher than the mean scores of individuals aged 20 years and younger.

When Table 9 is examined; it was observed that there was a negative and statistically significant correlation between DGASC total score of the participants and the total score of sportsmanship scale, and there was a positive and statistically significant correlation between the DGASC total score and age of the participants. It is seen that there is a negative and statistically significant correlation between the total score of sportsmanship scale and age variable of the participants. According to the results of this research; it can be said that increasing the digital game addiction levels of the participants is an important factor that negatively affects sportsmanship behaviors. However, the increase in digital game addiction levels in relation to age reveals that the time spent playing games is an important factor in addiction. On the other hand, the negative relationship between age variable and sportsmanship scores of the participants reveals that with increasing age, sportsmanship behavior levels decrease.

As a result; although there is no similar research on the subject when the literature is examined, the findings of the research on the variables discussed in the scope of the research will contribute significantly to the literature in terms of revealing the differences and relationships between the variables.

In similar researches; In particular, by using the "observation" method, which is an important study design of the qualitative research model, it is possible to confirm the results of the research by observing the sportsmanship behaviors of children with high digital game addiction in physical education and sports lessons.

\section{References}

Aksel, N., 2018. Analyzing the relationship between the digital game addiction of secondary school students and their both self-control and social tendency. Master's Thesis. Ordu University Institute of Social Sciences Department of Educational Sciences. 
Arslan, E., P. Bütün, M. Doğan, H. Dağ, C. Serdarzade and V. Arıca, 2014. Personal computer and internet usage in childhood. Izmir Behcet Uz Children's Hospital Journal, 4(3): 195-201.

Aydoğdu-Karaaslan, I., 2015. Digital games and digital violence awareness: A comperative analysis made on parents and children. The Journal of International Social Research, 8(36): 806-818.

Bülbül, H., T. Tunç and F. Aydİl, 2018. Game addiction in university students and its relationship with personality traits and academic perform. Academic Review of Economics and Administrative Sciences, 11(3): 97-111.

Buyukozturk, S., E. Kilic Cakmak, O. Akgun, E., S. The Black Sea and F. Demirel, 2016. Scientific research methods. Ankara: Pegem Academy.

Davis, R.A., 2001. A cognitive-behavioral model of pathological internet use. Computers in Human Behavior, 17(2): 187-195.Available at: https://doi.org/10.1016/s0747-5632(00)00041-8.

Demir, G.T. and H.İ. Cicioğlu, 2019. Investigation of the relationship between motivation of participation in physical activity and motivation of digital gaming. Spormetre, 17(3): 82-88.

Demir, G.T. and Z. Hazar, 2018. Digital gaming motivation scale : Validity and reliability study. Journal of Physical Education \& Sports Science, 12(2): 23-29.

Dolu, O., H. Büker and Ş. Uludağ, 2010. Effects of violent video games on children: An assessment on aggression, violence and delinquency. Turkish Journal of Forensic Sciences, 9(4): $54-75$.

Donati, M.A., F. Chiesi, G. Ammannato and C. Primi, 2015. Versatility and addiction in gaming: The number of video-game genres played is associated with pathological gaming in male adolescents. Cyberpsychology, Behavior, and Social Networking, 18(2): 129-132.

Erkuş, A., 2013. Scientific research process for behavioral sciences. Ankara: Seçkin.

Eryılmaz, S. and Ö. Çukurluöz, 2018. Examination of high school students digital addiction: Province of Ankara, Çankaya district sample. Electronic Journal of Social Sciences, 17(67): 889-912.

Gentile, D.A. and C.A. Anderson, 2006. Video games. Encyclopedia of Human Development, 3(8): 1303-1307.

Giles, J.W. and G.D. Heyman, 2005. Young children's beliefs about the relationship between gender and aggressive behavior. Child Development, 76(1): 107-121.

Gökçearslan, S. and A. Durakoğlu, 2014. An analysis of video game addiction levels among secondary school students according to several variables. Dicle University Journal of Ziya Gökalp Faculty of Education, 23(14): 419-435.

Griffiths, M., 2009. Online computer gaming: Advice for parents and teachers. Education and Health, 27(1): 3-6.

Griffiths, M.D. and A. Meredith, 2009. Videogame addiction and its treatment. Journal of Contemporary Psychotherapy, 39(4): 247253.Available at: https://doi.org/10.1007/s 10879-009-9118-4.

Güllü, S., 2018. A research on coach-athlete relationship and sportsmanship orientation of the athletes. Spormetre The Journal of Physical Education and Sport Sciences, 16(4): 190-204.

Harmandar, İ., H., 2004. Special teaching methods in physical education and sports. Ankara: Nobel.

Hazar, Z., 2016. Effect of games including physical activity on digital game addiction of age group middle-school students. Doctora Thesis. Gazi Unıversity. Institute of Educational Sciences. pp: 11-14.

Hazar, Z., K. Hazar, B. Gökyürek, M. Hazar and S. Çelikbilek, 2017. Investigation of the relationship between the level of playfulness, digital game addiction and aggression among secondary school students in terms of various variables. Journal of Human Sciences, 14(4): 4320-4332.Available at: https://doi.org/10.14687/jhs.v14i4.5035.

Hazar, Z., G. Tekkurşun Demir and H. Dalkıran, 2017. Investigation of the traditional game and digital games perceptıons of middle school students: Comparative metafor study. Spormetre, 15(4): 179-190.

Hazar, Z., D.G. Tekkurşun, S. Namli and A. Türkeli, 2017. Investigation of the relationship between digital game addiction and physical activity levels of secondary school students. Journal of Physical Education \& Sports Science, 11(3): 320-332.

Horzum, M.B., 2011. Examining computer game addiction level of primary school students in terms of different variables. Education and Science, 36(159): 56-67.

Horzum, M.B., T. Ayas and Ö. Çakırbalta, 2008. Computer game addiction scale for children. Turkish Journal of Psychological Counseling and Guidance, 3(30): 76-88.

Irmak, A.Y. and S. Erdogan, 2016. Digital game addiction in adolescents and young adults: A current overview. Turkish Journal of Psychiatry, 27(2): 1-10.

Kale, R. and E. Erşen, 2003. Introduction to physical education and sports sciences. Ankara: Nobel.

Karafil, A., Y., E. Atay, M. Ulaş and M. Melek, 2017. Investigation of the effect of participation in sports on physical education course sportsmanship behaviors. CBU Journal of Physical Education and Sport Sciences, 12(2): 18-23.

Karayağız-Muslu, G. and B. Bolışık, 2009. Internet usage among children and young people. TAF Prev Med Bull, 8(5): 445-450.

Kim, P.W., S.Y. Kim, M. Shim, C.-H. Im and Y.-M. Shon, 2013. The influence of an educational course on language expression and treatment of gaming addiction for massive multiplayer online role-playing game players. Computers \& Education, 63(5): $208-217$.

Kocaman, O., E. Aktepe and Y. Sonmez, 2017. An investigation of the relationship between possible internet addiction and aggression and empathy levels in high school students in isparta province. Anatolian Journal of Psychiatry, 18(6): 602-611.

Lieberman, D.A., M.C. Fisk and E. Biely, 2009. Digital games for young children ages three to six: From research to design. Computers in the Schools, 26(4): 299-313.Available at: https://doi.org/10.1080/07380560903360178.

Müller, K.W., M. Janikian, M. Dreier, K. Wölfling, M. Beutel, C. Tzavara, C. Richardson and A. Tsitsika, 2015. Regular gaming behavior and internet gaming disorder in European adolescents: results from a cross-national representative survey of prevalence, predictors, and psychopathological correlates. European Child \& Adolescent Psychiatry, 24(5): 565-574.

Pehlivan, Z., 2004. Sport in schools for improving the concept; fair-play. Spormetre The Journal of Physical Education and Sport Sciences, $2(2): 49-53$.

Sakin, M., 2007. Game virtual crisis is real. Ailem Magazine, $213(7): 18-23$.

Tiryaki, Ş., 1996. Determining the aggression levels of individuals who do sports: (a study in terms of team and individual sports). Mersin University, Institute of Health Sciences / Department of Physical Education and Sports Master Thesis. Mersin.

Türkmen, M. and S. Varol, 2015. Analysis of the effects of physical education and sport courses on the development of sportsmanship attitude of secondary school students. International Journal of Contemporary Educational Studies, 1(3): 78-83.

Yakup, K., 2013. Sportspersonship behavior scale in physical education course: Validity reliability study. Journal of Erzincan University Faculty of Education, 15(1): 96-114.

Yapan, H.T., 2007. Sports ethics. Gaziantep: Head Offset.

Yiğit, A.F. and A. Yalman, 2018. Impacts of digital games on behaviours and personality of children: The case of Gta 5 . Akdeniz Unıversty Journal of Faculty of Communication, 29: $163-118$.

Yıldıran, I., 2004. Fair play: Concept, view in Turkey and improving perspectives. Gazi Journal of Physical Education and Sports Science, $9(4): 3-16$.

Yurttaş, H., 2016. Investigation of aggression levels of university students who do sports and do not do sports. Master Thesis. Institute of Educational Sciences. Department of Physical Education and Sports Teaching. Atatürk Universty. 